\title{
Do early stages of lumbar intervertebral disc degeneration really cause instability? Evaluation of an in vitro database
}

\author{
Annette Kettler $\cdot$ F. Rohlmann $\cdot$ C. Ring • \\ C. Mack - H.-J. Wilke
}

Received: 10 February 2010/Revised: 18 September 2010/Accepted: 14 November 2010/Published online: 2 December 2010

(c) Springer-Verlag 2010

\begin{abstract}
Early stages of intervertebral disc degeneration are postulated to cause instability. In the literature, however, some authors report the opposite. These contradictory positions are probably supported by the mostly small number of segments which are investigated. The aim of this project therefore was to investigate the influence of intervertebral disc degeneration on lumbar spine rotational stability using a large data set. The flexibility data from all spine specimens tested in our institute so far were collected in a large in vitro database. From this database, all lumbar spine specimens were selected, which had been tested for flexibility under pure moment loads of $\pm 7.5 \mathrm{~N} \mathrm{~m}$ and for which radiographs were accessible. 203 segments met these criteria. Their radiographic degree of disc degeneration was determined on a scale from 0 (no degeneration) to 3 (severe degeneration) and their influence on the respective range of motion and neutral zone was examined. The different lumbar levels differ in flexibility, which increases the variability of the data if pooled together. To minimise this effect a statistical model was fitted. The model-based mean estimates showed a decrease of the range of motion from grade 0 to 3 in flexion/extension (by $3.1^{\circ}, p<0.05$ ) and lateral bending (by $3.4^{\circ}, p<0.05$ ). In contrast, in axial rotation the range of motion tended to increase; however,
\end{abstract}

\footnotetext{
A. Kettler $(\bowtie)$

SpineServ GmbH \& Co. KG, Soeflinger Strasse 100, 89077 Ulm, Germany

e-mail: annette.kettler@spineserv.de

C. Mack · H.-J. Wilke

Institute for Orthopaedic Research and Biomechanics,

University of Ulm, Ulm, Germany

F. Rohlmann · C. Ring

Institute of Biometry, University of Ulm, Ulm, Germany
}

not only from grade 0 to 1 but also towards grade 3 (by $\left.0.2^{\circ}\right)(p>0.05)$. The neutral zone was affected in a similar way but to a smaller degree $(p>0.05)$. In conclusion, the results indicated that early stages of intervertebral disc degeneration do not necessarily cause rotational instability. In contrast, stability increased in flexion/extension and lateral bending. Only in axial rotation stability tended to decrease.

Keywords Lumbar spine - Intervertebral disc . Degeneration · Instability · Biomechanics

\section{Introduction}

Early stages of intervertebral disc degeneration are often made responsible for spinal instability. This relationship was first hypothesised in 1982 by Kirkaldy-Willis and Farfan [12], who divided the clinical manifestation of degenerative changes in the lumbar spine in three stages: (1) temporary dysfunction, (2) unstable phase and (3) stabilisation.

Instability is supposed to cause low back pain. Various types of surgical implants exist to treat this condition, for example dynamic stabilisation devices. Besides some other effects, these implants are intended to restabilise unstable segments but still allow some movements in order to prevent the progression of adjacent level diseases. Based on the work by Kirkaldy-Willis and Farfan these implants could be used to treat the early, unstable phase of degeneration.

The three stages of degeneration postulated by KirkaldyWillis and Farfan are based on clinical observations. The main challenge in clinical studies is to define and accurately measure instability [18]. Mostly, the patients are 
asked to adopt a certain posture or to conduct a certain movement. The standardisation of this procedure is difficult. Furthermore, if radiographs are taken for evaluation, relatively high measurement errors have to be expected. External motion analysis systems may be used instead. They track the movements of markers attached to the skin. This, however, reflects the movements of the skin but not that of the underlying spinal structures. This is somewhat different in in vitro studies. The loading conditions can more easily be standardised and the measurements errors are expected to be smaller since the markers can directly be attached to the vertebral bodies.

So far, several in vitro studies have been carried out to investigate the effect of intervertebral disc degeneration on lumbar spine stability $[7,13,14,16,19]$. The results of these studies, however, vary considerably. Similarly to Kirkaldy-Willis and Farfan, some authors report about instability during the early stages of degeneration [7, 19], while others rather show the opposite $[13,14,16]$. These partially contradictive results are probably enforced by the relatively small number of specimens. Furthermore, mostly, several lumbar spine levels were pooled together, even though it is known they differ in stability.

The aim of the present study therefore was to analyse the influence of the degree of disc degeneration on the flexibility of lumbar spine segments based on the data from a large in vitro database after adjustment for the spinal level.

\section{Methods}

The in vitro flexibility data from all spine specimens tested in our institute during the last 10 years were collected in a large database. From this database, all lumbar spine specimens L1-2, L2-3, L3-4 and L4-5 were selected, which had been tested in flexion/extension, lateral bending and axial rotation under pure moment loads of $\pm 7.5 \mathrm{~N} \mathrm{~m}$ and for which radiographs in two planes were accessible. The flexibility tests had all been carried out in one and the same testing device [22]. Also, the loading conditions had always been the same: pure moment loads had been applied without axial preload, the five uncontrolled degrees of freedom had been unconstrained and the third loading cycle had been evaluated. The segment L5-S1 was not included in this study since there were only few data for this level in the database.

203 segments from 111 donors with an age of 19-99 years (median 56) met the above-mentioned selection criteria (Table 1). There had been no special selection processes for the specimens such that they can be assumed to represent the general population at the given age range. In axial rotation one range of motion value was missing and three neutral zone values. The selected segments had
Table 1 Specimens tested in this study

\begin{tabular}{lc}
\hline Number of donors & 111 \\
Age in years known from 107 donors & 18 \\
Minimum & 99 \\
Maximum & 56 \\
Median & 55.9 \\
Mean & 15.2 \\
Standard deviation & \\
Gender & \\
Female & 45 \\
Male & 61 \\
Unknown & 5 \\
Number of donors with $1,2,3$ or 4 segments & \\
1 segment & 51 \\
2 segments & 38 \\
3 segments & 12 \\
4 segments & 10 \\
Overall number of segments & \\
Flexion/extension ROM and NZ & 203 \\
Lateral bending ROM and NZ & 203 \\
Axial rotation ROM & 202 \\
Axial rotation NZ & 200 \\
\hline
\end{tabular}

been tested in specimens composed of up to four discs. From literature it is known that the range of motion of one and the same segment becomes smaller if it is tested in a polysegmental specimen compared to a monosegmental specimen [11].

The degree of intervertebral disc degeneration of each of the 203 segments was determined using the radiographs. According to the system of Wilke et al. [23] three criteria were rated: height loss, osteophytes and sclerosis. Each of these three parameters was classified 0 (no degeneration) to 3 (severe degeneration). Based on these individual ratings one overall degree of degeneration also ranging from 0 (no degeneration) to 3 (severe degeneration) (Fig. 1) was attributed to each disc.

Then, the influence of the overall radiographic degrees of degeneration on the respective range of motion (ROM) and neutral zone (NZ) values for flexion plus extension, right plus left lateral bending and left plus right axial rotation was examined. ROM was defined as the rotational movement of the segment (accuracy $\pm 0.1^{\circ}$ ) between an external load of +7.5 and $-7.5 \mathrm{~N} \mathrm{~m}$ (accuracy $\pm 0.1 \mathrm{~N} \mathrm{~m}$ ). $\mathrm{NZ}$ reflects the laxity of the segment at zero load $(0 \mathrm{~N} \mathrm{~m})$.

The whole data set consisted of a mixture of independent and dependent data: the number of discs per donor varied as well as the number of discs per specimen (monoand polysegmental specimens) and different lumbar levels were included (Table 1). 



Fig. 1 Examples of the four degrees of degeneration

The most commonly used statistical methods assume either independent data or paired data but not a mixture of both. The solution for this problem was to use a general linear model, which was specifically fitted to the data. A general linear model is a statistical model that incorporates normally distributed dependent variables (e.g., ROM and NZ) and categorical or continuous independent variables (e.g., degree of degeneration). It examines the linear relationship between both types of variables and can be adapted to the respective research question. For the present study it was adapted such that it accounted for the abovementioned dependencies within the data. It allowed examining the simultaneous influence of spinal level and degeneration on ROM and NZ as well as their interaction.

Before application of the model, the data was checked for normal distribution, which was assumed by the model. If there was no normal distribution, the respective outcome variable, i.e., ROM or $\mathrm{NZ}$, was transformed using the natural logarithm and the model was formulated with the transformed values as dependent variable. A transformation was not necessary for ROM but had to be conducted for NZ in flexion/extension and lateral bending. In case of the NZ in axial rotation the transformation was not optimal, thus the original data were used even though they did not fulfil the normality assumption.

Thereafter, different dependency structures were investigated in the model. To select the most appropriate dependency structure the AIC-criterion (Akaike information criterion) was used [4]. This criterion is a measure of the goodness of fit of an estimated statistical model. Since the compound symmetry structure (the correlations between all pairs of measures are the same) led to the smallest AIC values this structure was included in all final models. If the interaction had no significant influence on the dependent variable (level of significance 5\%), this effect was removed from the model. The fixed effects of spinal level and degeneration were kept in the model irrespectively of their $p$ value.

As main result the model-based mean estimates with 95\% confidence intervals are shown with respect to the degree of degeneration. In case of the log-transformed NZ, the presented mean values and confidence intervals are the back-transformed model estimates. Additionally, the original, not adjusted mean values are shown for comparison. $p$ values are reported for the fixed effect of the degree of degeneration and the spinal level on the outcome parameters ROM and NZ for each of the three loading directions. Since this analysis had an explorative character no adjustment for multiple testing was carried out. The $p$ values therefore underline trends but do not statistically prove any differences. Paired comparisons between each pair of degree of degeneration or each pair of spinal level were not conducted. This was done in order not to artificially increase the number of not adjusted $p$ values. These might easily become misleading since differences may be found, which are significant only by chance.

\section{Results}

The statistical model showed that the degree of degeneration had an influence on ROM in flexion/extension ( $p=0.014$; not corrected for multiple comparisons due to explorative character of this study) and lateral bending $(p<0.001)$ (Table 2). For the spinal level all $p$ values were $<0.01$ for both ROM and NZ in all loading planes except for ROM in lateral bending.

Table $2 p$ values from the final general linear model for the fixed effects degree of degeneration and spinal level

\begin{tabular}{|c|c|c|c|c|c|c|}
\hline & \multicolumn{2}{|l|}{ FE } & \multicolumn{2}{|l|}{ LB } & \multicolumn{2}{|l|}{$\mathrm{AR}$} \\
\hline & ROM & NZ & ROM & $\mathrm{NZ}$ & ROM & NZ \\
\hline $\begin{array}{l}\text { Degree of } \\
\text { degeneration }\end{array}$ & 0.014 & 0.835 & $<0.001$ & 0.103 & 0.695 & 0.724 \\
\hline Spinal level & $<0.001$ & $<0.001$ & 0.102 & 0.004 & $<0.001$ & $<0.001$ \\
\hline
\end{tabular}

$p$ values $<0.05$ are highlighted in bold. The $p$ values indicate whether there is any effect of the degree of degeneration or the spinal level on ROM and NZ in each of the three loading directions. A paired comparison was not carried out do to the explorative character of this study

$R O M$ range of motion, $N Z$ neutral zone, $F E$ flexion plus extension, $L B$ right plus left lateral bending, $A R$ left plus right axial rotation 
Fig. 2 Range of motion (ROM, dark bar) and neutral zone (NZ, light bar) in flexion plus extension with respect to the degree of degeneration. Left original data before application of the statistical model (mean and standard deviation, all levels from L1-L2 to L4-L5 were pooled together); right estimates of the statistical model (mean and confidence intervals). $n$ number of segments per degree of degeneration

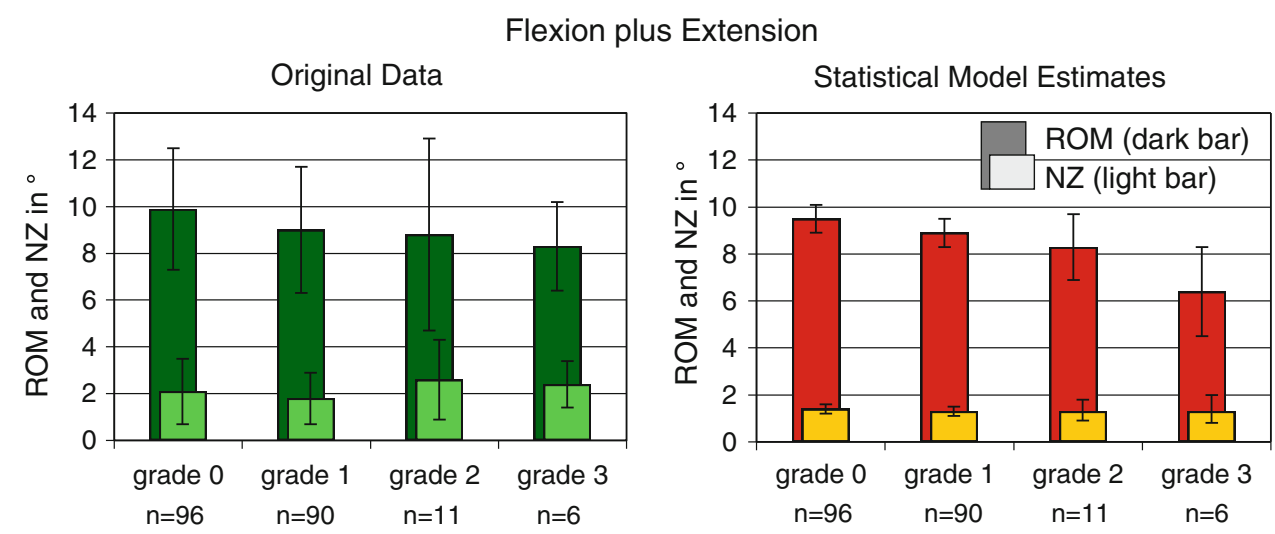

Table 3 Mean increase of range of motion and neutral zone with respect to grade 0 in degrees

\begin{tabular}{|c|c|c|c|c|c|c|}
\hline & \multicolumn{2}{|l|}{$\mathrm{FE}$} & \multicolumn{2}{|l|}{ LB } & \multicolumn{2}{|l|}{$\mathrm{AR}$} \\
\hline & ROM & $\mathrm{NZ}$ & ROM & $\mathrm{NZ}$ & ROM & $\mathrm{NZ}$ \\
\hline Grade 0 & 0.0 & 0.0 & 0.0 & 0.0 & 0.0 & 0.0 \\
\hline Grade 1 & -0.6 & -0.1 & -1.4 & -0.3 & 0.3 & 0.1 \\
\hline Grade 2 & -1.2 & -0.1 & -2.0 & -0.2 & 0.2 & 0.2 \\
\hline Grade 3 & -3.1 & -0.2 & -3.4 & -0.5 & 0.2 & 0.2 \\
\hline
\end{tabular}

Estimates of the statistical model are presented. In case of the logtransformed NZ (FE and LB) the estimates are back-transformed

$R O M$ range of motion, $N Z$ neutral zone, $F E$ flexion plus extension, $L B$ right plus left lateral bending, $A R$ left plus right axial rotation

Table 4 Mean range of motion and neutral zone normalised to the mean value of grade $0(=100 \%)$

\begin{tabular}{|c|c|c|c|c|c|c|}
\hline & \multicolumn{2}{|l|}{$\mathrm{FE}$} & \multicolumn{2}{|l|}{ LB } & \multicolumn{2}{|l|}{$\mathrm{AR}$} \\
\hline & ROM\% & NZ\% & ROM\% & $\mathrm{NZ} \%$ & ROM \% & NZ\% \\
\hline Grade 0 & 100 & 100 & 100 & 100 & 100 & 100 \\
\hline Grade 1 & 94 & 93 & 87 & 82 & 107 & 126 \\
\hline Grade 2 & 88 & 93 & 81 & 86 & 104 & 137 \\
\hline Grade 3 & 67 & 88 & 67 & 67 & 105 & 146 \\
\hline
\end{tabular}

Estimates of the statistical model are presented. In case of the logtransformed NZ (FE and LB) the estimates are back-transformed

$R O M$ range of motion, $N Z$ neutral zone, $F E$ flexion plus extension, $L B$ right plus left lateral bending, $A R$ left plus right axial rotation

In flexion plus extension, the model-based mean estimates of the ROM showed a decrease from $9.5^{\circ}$ in grade 0 to $6.4^{\circ}$ in grade 3 ( $p=0.0023$ ) (Fig. 2 ; Tables 3,4$)$. This decrease also included the early stages of degeneration (grades 1 and 2). In contrast, NZ stayed almost the same with $1.4^{\circ}$ in grade 0 and $1.3^{\circ}$ in grade 3 . The original data before application of the statistical model, showed a similar trend for ROM, which, however, was less distinct. In contrast, concerning NZ, the original data rather tended to increase with increasing degree of degeneration.
In right plus left lateral bending the trends were very similar to those observed in flexion/extension (Fig. 3; Tables 3,4). The model mean estimates of ROM decreased from $10.2^{\circ}$ in grade 0 to $6.8^{\circ}$ in grade 3 , which corresponds to a decrease by $33 \%(p=0.0011)$. This trend was also detectable with the original data. The NZ estimates from the statistical model decreased somewhat stronger in lateral bending than in flexion/extension. In grade 0 a mean neutral zone of $1.5^{\circ}$ was estimated by the statistical model but in grade 3 only $1.0^{\circ}$.

In left plus right axial rotation the statistical model estimates showed almost no difference between the four degrees of degeneration for ROM (Fig. 4; Tables 3, 4). In contrast, the original data showed an increase from $3.9^{\circ}$ in grade 0 to $5.2^{\circ}$ in grade 3 . A slight increase would also be possible with the model estimates taking into consideration the relatively large confidence intervals. Similarly, NZ more tended to increase in the original data (from $0.5^{\circ}$ to $0.8^{\circ}$ ) than in the statistical model data (from $0.4^{\circ}$ to $0.6^{\circ}$ ).

\section{Discussion}

The aim of this study was to evaluate the relationship between intervertebral disc degeneration and segmental rotational instability. For this purpose, a statistical model was fitted based on in vitro data from 203 lumbar spine segments. This model allowed to examine all data together, taking into account the influence of the lumbar levels, which are known to differ in flexibility. This difference between the lumbar levels was also detected in the present study in almost all cases $(p<0.01$; not corrected for multiple comparisons due to explorative character of this study) (Table 2).

The results did not confirm the instability hypothesis proposed by Kirkaldy-Willis and Farfan [12]. In contrast, in flexion/extension and lateral bending ROM and NZ decreased from no to severe degeneration. Only in axial rotation ROM and NZ tended to increase, however, not 
Fig. 3 Range of motion (ROM, dark bar) and neutral zone (NZ, light bar) in left plus right lateral bending with respect to the degree of degeneration. Left original data before application of the statistical model (mean and standard deviation, all levels from L1-L2 to L4-L5 were pooled together); right estimates of the statistical model (mean and confidence intervals). $n$ number of segments per degree of degeneration

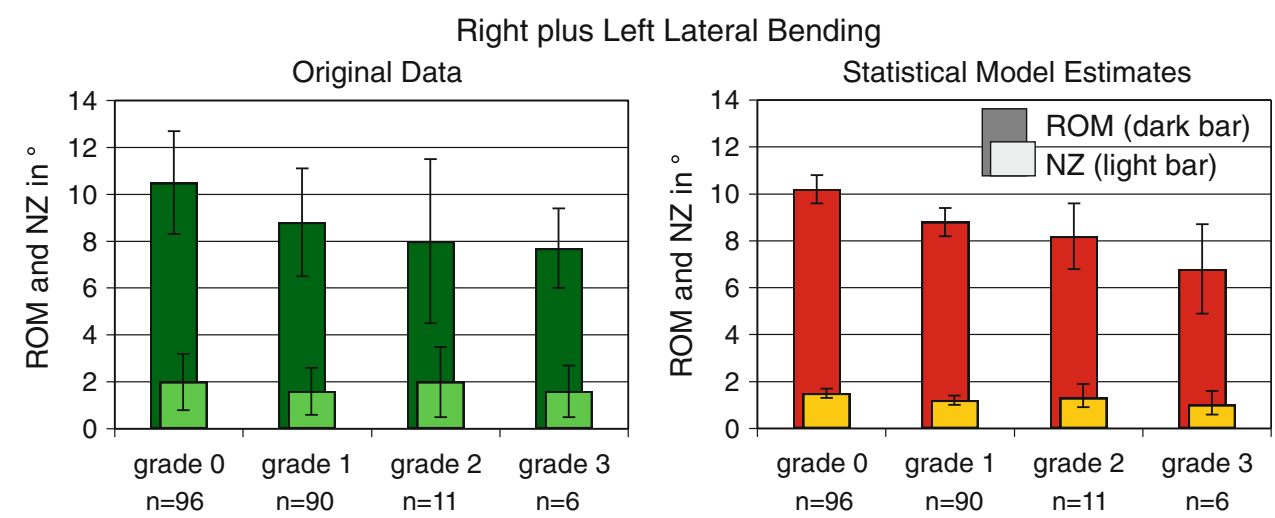

Left plus Right Axial Rotation

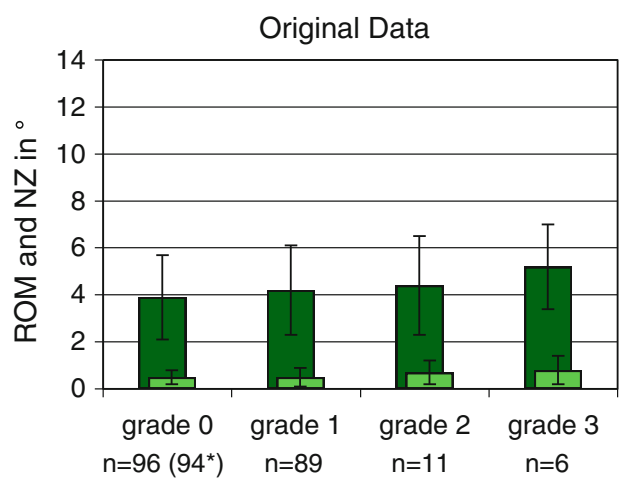

Fig. 4 Range of motion (ROM, dark bar) and neutral zone (NZ, light bar) in left plus right axial rotation with respect to the degree of degeneration. Left original data before application of the statistical model (mean and standard deviation, all levels from L1-L2 to L4-L5

only for mild and moderate degeneration but continuously towards severe degeneration.

Compared to other in vitro studies reported in the literature, both, similarities and differences were found (Table 5). The similarities are strongest in axial rotation. In this loading direction, three studies revealed an increasing ROM with increasing degree of degeneration $[13,14,16]$. In lateral bending two found a continuously decreasing ROM as seen in the present study $[14,16]$, while in flexion/ extension there was only one other study indicating such a decrease [14]. The strongest differences between the present study and those reported in the literature were found compared to Fujiwara et al. and Tanaka et al. [7, 19]. These two studies, which are both from the same group of researchers, found an initial increase of ROM for mild or moderate degeneration, which was followed by a final decrease towards severe degeneration.

Thus, Fujiwara et al. and Tanaka et al. support the instability hypothesis of Kirkaldy-Willis and Farfan, while the others do not. This inconsistency may have different reasons. First, in all former in vitro studies, various lumbar levels were pooled together without accounting for possible

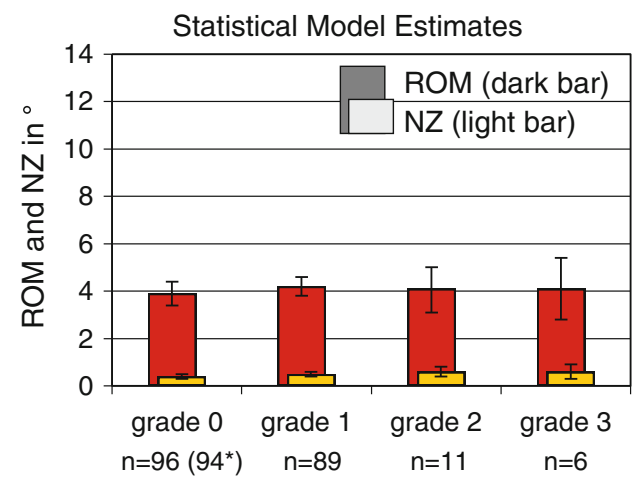

were pooled together); right estimates of the statistical model (mean and confidence intervals). $n$ number of segments per degree of degeneration. *Two single values less for NZ than for ROM

differences. Furthermore, different grading systems were used. While in the present study and in one part of that of Mimura et al., a radiographic system was used, others were based on magnetic resonance images, discography or, most commonly, on macroscopic sections (Table 5). The systems used to grade these macroscopic sections were those of Nachemson [15], and Vernon-Roberts [21] which are both based on transverse sections through the disc, and the one of Thompson et al. [20], which is based on sagittal sections [10]. Fujiwara et al. and Tanaka et al., who used the system of Thompson et al. stated that greater motion generally was found in grades III and IV, in which radial tears of the annulus fibrosus were found. Disc space collapse and formation of osteophytes as found in grade $\mathrm{V}$, which is the highest degree of degeneration in this grading system, resulted in stabilisation of the motion segment. The stabilising effect of osteophytes has also been described by Al-Rawahi et al. [3], who found that the resistance to bending moments in flexion, extension, and left and right lateral bending was reduced by $49,36,36$, and $35 \%$. Thus, in case of the studies of Fujiwara et al. and Tanaka et al., tears were found in grades III and IV, while osteophytes were 
Table 5 Summary of in vitro studies, which investigated the influence of intervertebral disc degeneration on range of motion

\begin{tabular}{|c|c|c|c|c|c|c|c|c|}
\hline Study & $\begin{array}{l}\text { Number of discs } \\
\text { (donors) }\end{array}$ & $\begin{array}{l}\text { Age } \\
\text { range }\end{array}$ & Classification system & Grades & Flexibility tests & $\begin{array}{l}\text { ROM in } \\
\text { flexion/ex } \\
\text { tension }\end{array}$ & $\begin{array}{l}\text { ROM in } \\
\text { lateral } \\
\text { bending }\end{array}$ & $\begin{array}{l}\text { ROM in } \\
\text { axial } \\
\text { rotation }\end{array}$ \\
\hline Present study & $\begin{array}{l}203 \text { (111) L1-2 to } \\
\text { L4-5 }\end{array}$ & $18-99$ & $\begin{array}{l}\text { Radiographic: according to Wilke et al } \\
\text { [23] }\end{array}$ & 0 (normal) to 3 & $\begin{array}{l}\text { Pure moments } \\
\pm 7.5 \mathrm{~N} \mathrm{~m}\end{array}$ & & & \\
\hline $\begin{array}{l}\text { Mimura et al. } \\
{[14]}\end{array}$ & $\begin{array}{l}47(12) L 2-3 \text { to } \\
L 5-S 1\end{array}$ & $35-64$ & $\begin{array}{l}\text { Radiographic: own system } \\
\text { Macroscopic: transverse slices } \\
\text { according to Nachemson [15] }\end{array}$ & $\begin{array}{l}1 \text { (normal or mild) to } 4 \\
1 \text { (normal) to } 4 \text { (grades } \\
1 \text { and } 2 \text { pooled together) }\end{array}$ & $\begin{array}{l}\text { Pure moments } \\
\pm 10 \mathrm{~N} \mathrm{~m}\end{array}$ & & & \\
\hline $\begin{array}{l}\text { Krismer et al. } \\
{[13]}\end{array}$ & $\begin{array}{l}36(15) \text { T12-L1 to } \\
\text { L4-5 }\end{array}$ & $20-92$ & $\begin{array}{l}\text { Macroscopic: transverse slices } \\
\text { according to Nachemson [15] }\end{array}$ & 1 (normal) to 4 & $\begin{array}{l}\text { Pure moments } \\
\pm 8.5 \mathrm{~N} \mathrm{~m} \text { (lateral } \\
\text { bending and axial } \\
\text { rotation only) }\end{array}$ & \multicolumn{3}{|c|}{$\begin{array}{l}\text { Similar tendencies for radiographic } \\
\text { and discographic grading system }\end{array}$} \\
\hline $\begin{array}{l}\text { Oxland et al. } \\
{[16]}\end{array}$ & $\begin{array}{l}24 \text { (?) L1-2 to } \\
\text { L5-S1 }\end{array}$ & $?$ & $\begin{array}{l}\text { Macroscopic: transverse slices } \\
\text { and removed nucleus material } \\
\text { according to Vernon-Roberts [21] }\end{array}$ & 1 (normal) to 4 & $\begin{array}{l}\text { Pure moments } \\
\pm 10 \mathrm{~N} \text { m plus } \\
200 \mathrm{~N} \text { axial } \\
\text { preload }\end{array}$ & & & \\
\hline $\begin{array}{l}\text { Fujiwara et al. } \\
\text { [7] }\end{array}$ & $\begin{array}{l}110(44) \mathrm{T} 12-\mathrm{L} 1 \\
\text { to } \mathrm{L} 5-\mathrm{S} 1\end{array}$ & $39-88$ & $\begin{array}{l}\text { Magnetic resonance images: } \\
\text { sagittal slices according to } \\
\text { Thompson et al. [20] }\end{array}$ & $\begin{array}{l}1 \text { (normal) to } 5 \\
\text { (grade } 1 \text { not evaluated) }\end{array}$ & $\begin{array}{l}\text { Pure moments } \\
\pm 6.6 \mathrm{~N} \mathrm{~m}\end{array}$ & & & \\
\hline $\begin{array}{l}\text { Tanaka et al. } \\
\text { [19] }\end{array}$ & $\begin{array}{l}114(47) \mathrm{T} 12-\mathrm{L} 1 \\
\text { to } \mathrm{L} 5-\mathrm{S} 1\end{array}$ & $39-87$ & $\begin{array}{l}\text { Macroscopic: sagittal slices } \\
\text { according to Thompson et al. [20] }\end{array}$ & 1 (normal) to 5 & $\begin{array}{l}\text { Pure moments } \\
\pm 5.7 \mathrm{~N} \mathrm{~m}\end{array}$ & $\begin{array}{l}\text { Similar } \\
\text { based }\end{array}$ & $\begin{array}{l}\text { encies } \\
\text { gnetic }\end{array}$ & $\begin{array}{l}\text { s only; } \\
\text { ng system } \\
\text { ce images }\end{array}$ \\
\hline
\end{tabular}

ROM range of motion, \# original data reported for flexion and extension separately

probably found mainly in grade $\mathrm{V}$. If these signs of degeneration are not evaluated, e.g., osteophytes in case of transverse sections through the disc, or fissures in case of radiographic grading systems, or if they are attributed to other degrees of degeneration the results may become very different. To date, there is no grading system and grading methodology available that covers all the different aspects of degeneration. It would therefore be important to know more about the agreement between the various grading systems. Also, in future it would be interesting to evaluate how ROM and NZ depend on each single sign of degeneration separately. This has been done for creep loading and endplate damage as models for early degeneration (flexibility in flexion/extension and lateral bending strongly increases) and osteophytes (flexibility decreases) [3, 24]. However, creep loading and endplate damage do not necessarily represent early degeneration, which is also characterised by biochemical changes and manual excision of osteophytes, as carried in the study mentioned above, may easily cause artificial instability.

A further reason for the inconsistency of the various studies concerning the relationship between degree of degeneration and spinal instability could be the study design: Kirkaldy-Willis and Farfan suggested that spinal flexibility changes over time. The present study does not directly cover this time-dependency since it has a cross-sectional design. This limitation is expected to be minimised by the large number of specimens included into the data set. Furthermore, all cadaveric in vitro studies are necessarily cross-sectional studies. Yet, they show different results.

Another hypothesis says that early instability does not occur in all cases and, thus, may be hidden in some studies. As mentioned above, Zhao et al. [24] could show that artificial disc narrowing by creep or endplate damage used to simulate early degeneration increases spinal flexion and lateral bending. If degeneration starts in this way, instability may occur, but if degeneration is associated with significant biochemical changes and if it goes hand in hand with osteophyte formation stability probably increases [2].

In most in vitro studies summarised in Table 5, axial rotation behaved differently compared to flexion/extension and lateral bending. While in the latter loading directions, ROM rather decreased with increasing degeneration, it tended to increase in the former one. From a biomechanical point of view this observation can be explained in three ways. First, during axial rotation shear loads are acting on the disc. Intervertebral discs with fissures and delamination may not be able to resist this load component as effectively as healthy discs. Therefore, a loss of stability in axial rotation is expected. In contrast, during flexion/extension and lateral bending movements, compressive and tensile loads are the most important load components. The resistance of the disc against these loads is assumed to be less affected by fissures and delamination. This hypothesis is 
supported by Krismer et al. who could show that the increase of flexibility in axial rotation was related to the degree of degeneration, where fissures occurred [13]. The second biomechanical explanation is based on the facet joints. These joints are assumed to restrict axial rotation movements to different degrees depending on the alignment of the segment. The more the segment goes into kyphosis, the later the restriction of the movements becomes effective. In cases of degenerative kyphosis [5] increasing axial rotation movements may therefore be expected. Finally, a degenerative loss of cartilage in the facet joints may also contribute to the decreasing stability in axial rotation $[1,8]$.

The definition of instability is difficult and controversially discussed. Clinically, it may be defined as a condition where a physiologic load induces abnormally large deformations [6]. Yet, the question remains, how to measure these deformations. In vitro ROM is often used to quantify instability. The data reported in Table 5 are all based on this parameter. However, some authors additionally report other parameters such as NZ [14, 16], neutral zone ratio (=NZ/ROM) [14], coupled rotations [13] or translations $[13,19]$. Other authors even report about parameters such as disc geometry and disc deformation to measure instability [9]. In the past, NZ was claimed to be more sensitive concerning instability than ROM [17], which sometimes was even claimed to define hypermobility rather than instability, which should be quantified using the NZ/ROM ratio. However, NZ is a parameter, which can only be measured in vitro. In vivo it might even not exist due to muscular stabilisation. In contrast, translations can be measured both in vitro and in vivo. However, this parameter is technically more difficult to investigate since it needs to be referred to predefined landmarks.

In conclusion, the results of this study, which includes data from 203 lumbar spine segments, indicated that early stages of intervertebral disc degeneration do not necessarily cause rotational instability. In contrast, in the present study, stability increased in flexion/extension and lateral bending from no to severe degeneration. Only in axial rotation stability tended to decrease.

\section{Conflict of interest None.}

\section{References}

1. Adams MA, Hutton WC (1981) The relevance of torsion to the mechanical derangement of the lumbar spine. Spine 6(3):241-248

2. Adams MA, Roughley PJ (2006) What is intervertebral disc degeneration, and what causes it? Spine 31(18):2151-2161

3. Al-Rawahi M, Luo J, Pollintine P, Dolan P, and Adams MA (2010) Mechanical function of vertebral body osteophytes, as revealed by experiments on cadaveric spines. Spine (Epub ahead of print)
4. Burnham KP, Anderson DR (2002) Model selection and multimodel inference: a practical information-theoretic approach. New York, Springer, pp 60

5. Farfan HF (1980) The pathological anatomy of degenerative spondylolisthesis. A cadaver study. Spine 5(5):412-418

6. Farfan HF, Gracovetsky S (1984) The nature of instability. Spine 9(7):714-719

7. Fujiwara A, Lim TH, An HS, Tanaka N, Jeon CH, Andersson GB, Haughton VM (2000) The effect of disc degeneration and facet joint osteoarthritis on the segmental flexibility of the lumbar spine. Spine 25(23):3036-3044

8. Heuer F, Schmidt H, Klezl Z, Claes L, Wilke HJ (2007) Stepwise reduction of functional spinal structures increase range of motion and change lordosis angle. J Biomech 40(2):271-280

9. Ito M, Tadano S, Kaneda K (1993) A biomechanical definition of spinal segmental instability taking personal and disc level differences into account. Spine 18(15):2295-2304

10. Kettler A, Wilke HJ (2006) Review of existing grading systems for cervical or lumbar disc and facet joint degeneration. Eur Spine $\mathbf{J}$ 15:705-718

11. Kettler A, Wilke HJ, Haid C, Claes L (2000) Effects of specimen length on the monosegmental motion behavior of the lumbar spine. Spine 25(5):543-550

12. Kirkaldy-Willis WH, Farfan HF (1982) Instability of the lumbar spine. Clin Orthop Relat Res (165):110-123

13. Krismer M, Haid C, Behensky H, Kapfinger P, Landauer F, Rachbauer F (2000) Motion in lumbar functional spine units during side bending and axial rotation moments depending on the degree of degeneration. Spine 25(16):2020-2027

14. Mimura M, Panjabi MM, Oxland TR, Crisco JJ, Yamamoto I, Vasavada A (1994) Disc degeneration affects the multidirectional flexibility of the lumbar spine. Spine 19(12):1371-1380

15. Nachemson A (1960) Lumbar intradiscal pressure. Experimental studies on post-mortem material. Acta Orthop Scand Suppl 43:43

16. Oxland TR, Lund T, Jost B, Cripton P, Lippuner K, Jaeger P, Nolte LP (1996) The relative importance of vertebral bone density and disc degeneration in spinal flexibility and interbody implant performance. An in vitro study. Spine 21(22):2558-2569

17. Panjabi MM (1992) The stabilizing system of the spine. Part II. Neutral zone and instability hypothesis. J Spinal Disord 5(4):390-396 (discussion 397)

18. Penning L, Wilmink JT, van Woerden HH (1984) Inability to prove instability. A critical appraisal of clinical-radiological flexion-extension studies in lumbar disc degeneration. Diagn Imaging Clin Med 53(4):186-192

19. Tanaka N, An HS, Lim TH, Fujiwara A, Jeon CH, Haughton VM (2001) The relationship between disc degeneration and flexibility of the lumbar spine. Spine J 1(1):47-56

20. Thompson JP, Pearce RH, Schechter MT, Adams ME, Tsang IK, Bishop PB (1990) Preliminary evaluation of a scheme for grading the gross morphology of the human intervertebral disc. Spine 15(5):411-415

21. Vernon-Roberts B, Pirie CJ (1973) Healing trabecular microfractures in the bodies of lumbar vertebrae. Ann Rheum Dis 32(5):406-412

22. Wilke HJ, Claes L, Schmitt H, Wolf S (1994) A universal spine tester for in vitro experiments with muscle force simulation. Eur Spine J 3(2):91-97

23. Wilke HJ, Rohlmann F, Neidlinger-Wilke C, Werner K, Claes L, Kettler A (2006) Validity and interobserver agreement of a new radiographic grading system for intervertebral disc degeneration: Part I. Lumbar spine. Eur Spine J 15(6):720-730

24. Zhao F, Pollintine P, Hole BD, Dolan P, Adams MA (2005) Discogenic origins of spinal instability. Spine 30(23):2621-2630 